\title{
A CONSTITUIÇÃO
}

DO ETHOS

DISCURSIVO

EM VIDEOAULAS

NA INTERNET:

\section{A FIGURA DO PROFESSOR- APRESENTADOR}

\section{LA CONSTITUCIÓN DEL ETHOS DISCURSIVO EN VIDEOCLASES EN INTERNET: LA FIGURA DEL PROFESOR-PRESENTADOR}

\author{
THE CONSTITUTION OF THE DISCURSIVE ETHOS IN VIDEO LESSONS ON THE INTERNET: \\ THE FIGURE OF THE TEACHER-PRESENTER
}

Simone Cristina Mussio*

Faculdade de Tecnologia de Jahu

\begin{abstract}
RESUMO: Em razão da expansão das mídias digitais, as quais têm possibilitado a proliferação de gêneros antes restritos somente ao âmbito acadêmico, como é o caso, por exemplo, das aulas transformando-se agora aulas em vídeo; este trabalho tem como objetivo observar como se constitui o ethos de professores presentes em videoaulas de escrita/redação científica inseridas na internet. Tem, assim, como meta perceber como se dão as formas de apresentação dos "professores-apresentadores" de tais aulas digitais, através de suas imagens, bem como de seus discursos. No processo de interação com o outro, pudemos perceber, neste estudo, como o "professor-apresentador" das videoaulas analisadas passa a se constituir por meio de distintos ethé, de acordo com os comportamentos assumidos durante a exposição das informações trazidas nas aulas em vídeo. Nesse sentido, notamos também como os acabamentos de tais aulas dialogam com o caráter telejornalístico e cinematográfico de sua produção.
\end{abstract}

PALAVRAS-CHAVE: Ethos discursivo. Videoaulas. Internet. Professor-apresentador.

RESUMEN: Debido al aumento excesivo de los géneros del discurso, originados según la expansión de los medios digitales, los cuales han permitido la proliferación de géneros previamente restringidos solo a los medios académicos, como es el caso, por ejemplo, de las clases que ahora se están convirtiendo en videoclases, el presente trabajo tiene como objetivo observar cómo es el ethos de los profesores presentes en videoclases de escritura/redacción científica en Internet. Por lo tanto, tiene como meta 
comprender cómo ocurren las presentaciones de los "profesores-presentadores" de tales clases digitales, a través de sus imágenes, así como de sus discursos En el proceso de interacción con el otro, nos dimos cuenta, en este estudio, como el "profesor-presentador" de las videoclases analizadas se constituyen de distintos ethé, de acuerdo con las conductas realizadas durante la exposición de las informaciones señalas en las clases en vídeo. En este sentido, también hemos notado cómo los acabamientos de las clases dialogan con el carácter teleperiodístico y cinematográfico de su producción.

PALABRAS CLAVE: Ethos discursivo. Videoclases. Internet. Profesor-presentador.

ABSTRACT: Due to the excessive increase of discourse genres originated due to the expansion of digital media, which have enabled the proliferation of genres previously restricted to the academic field only, for example the classroom lessons now becoming video lessons, this paper aims to observe how the ethos of teachers is presented in video lessons of scientific writing on the Internet. Therefore, it has as a goal to understand how the presentation of the "teachers-presenters" of such digital lessons occur, based on images, as well as speeches. In the process of interaction with the other, with this study we have perceived how the "teacher-presenter" of the analyzed video lessons is constituted by distinct ethé, according to the behaviors assumed during the exposure of the information in the lessons. In this sense, we also noticed how the completion of the video lessons dialogue with the production's characters of television journalism and cinema.

KEYWORDS: Discursive ethos. Video lessons. Internet. Teacher-presenter.

\section{INTRODUÇÃO}

Com a crescente expansão e domínio das mídias audiovisuais, a preocupação com a imagem, bem como com as formas de apresentação em variados meios comunicacionais são cada vez mais relevantes. Logo, em decorrência desse cenário, novos recursos tecnológicos, originados a partir de diferentes mídiuns (suportes), têm interferido nas práticas de produção e interpretação de inúmeros gêneros discursivos, principalmente os digitais.

Nesse sentido, objetivamos analisar de que modo se configura o ethos de professores presentes em videoaulas de escrita/redação científica a partir da inclusão deste gênero no ciberespaço. Para isso, tomamos como corpus do nosso estudo videoaulas produzidas para os cursos "Escrita Científica: Produção de Artigos de Alto Impacto" e "Método Lógico para Redação Científica", ambos inseridos no YouTube. Para os efeitos de sentido produzidos através deste trabalho, cabe, no entanto, aqui ressaltar que os cursos acima referidos foram produzidos exclusivamente para serem transmitidos via internet, sendo a plataforma do YouTube a principal responsável por difundi-los. Logo, a escolha de tal corpus se deu justamente por tais aulas se destinarem ao ambiente web e por se constituírem através de cursos completos de escrita/redação científica, ou seja, pela exposição de várias aulas sobre o tema e não somente a divulgação de apenas uma temática sobre o assunto.

Referindo-nos às suas características estilísticas, tencionamos perceber como se dá a caracterização de tais "professoresapresentadores" por meio de seu ethos discursivo. Para explicitar o modo como configuramos nossas análises, cabe aqui ressaltar que nos baseamos não apenas em imagens fornecidas pelas videoaulas, bem como também em excertos dos discursos dos "professores-apresentadores" dos cursos analisados. Para isso, utilizamos as siglas EC (Escrita Científica) e RC (Redação Científica) nas análises efetuadas, o recurso do negrito para destacar as partes que desejamos realçar, assim como definimos, entre parêntesis, após os trechos transcritos, a quais aulas tais trechos se referem, uma vez que tais cursos são compostos por inúmeras videoaulas.

\section{A IMPORTÂNCIA DO ETHOS NA CARACTERIZAÇÃO DE NOVOS GÊNEROS DISCURSIVOS}

Uma vez que todo discurso sugere uma imagem dos indivíduos circunscritos no processo interativo de comunicação, haja vista que, ao se projetar um modo de dizer, não se tem a possibilidade de se desconsiderar as consequências de tal ato, de modo a provocar a construção de uma imagem que condiciona uma determinada ação comunicativa, os participantes dessa interação passam a 
desempenhar poderes uns sobre os outros através de posições e papéis sociais definidores de caráter definidos no momento da enunciação.

A partir da enunciação, há o projetar de um autorretrato, o qual encerra a representação de uma autoimagem que tem por finalidade a produção de uma imagem daquele que enuncia. Esse autorretrato discursivo, desde os gregos antigos, é denominado ethos. Enquanto, na Grécia, por meio de Aristóteles, a imagem criada e mostrada pelo orador no momento da enunciação, a qual tinha como intuito o convencimento do seu destinatário, não correspondia, necessariamente, à identidade real daquele que enuncia; para os romanos, o ethos estava associado aos atributos reais do orador, à sua moral, não incidindo, propriamente, na imagem discursiva criada pelo orador. Foi seguindo o esteio do pensamento grego que os estudos linguísticos alicerçaram sua construção teórica da noção de ethos.

Maingueneau (2013) baliza o conceito de ethos na retórica aristotélica, definindo-o como a suposta imagem que o enunciador pretende dar de si mesmo, não apenas pelas suas afirmações com relação às suas qualidades, mas através do modo e do tom de voz utilizados, inferidos pelo ouvinte (destinatário) na totalidade daquilo que é enunciado. Assim, o ethos não se situa no enunciado, mas na enunciação. O ethos se materializa no sujeito construído no discurso, é, logo, uma imagem do autor, não o autor real (pessoa), mas um autor discursivo (erigido pela tessitura e pela textura do texto), segundo os dizeres de Discini (2008).

O conceito de ethos, ao ser recuperado e ampliado pela Análise do Discurso, segundo as discussões de Maingueneau (2008), apresenta situações discursivas associadas a enunciados orais ou escritos, sendo estes últimos atrelados à modalidade verbal, visual ou verbo-visual, podendo representar pessoas ou até mesmo instituições. É, portanto, caracterizado como o meio pelo qual a personalidade do enunciador é revelada, utilizando-se dos dizeres de Roland Barthes ao asseverar que estes “[...] são traços de caráter que o orador deve mostrar ao auditório (pouco importa sua sinceridade) para causar boa impressão: são os ares que assume ao se apresentar. [...] O orador enuncia uma informação, e ao mesmo tempo diz: eu sou isto, eu não sou aquilo" (BARTHES, 1966, p. 212 apud MAINGUENEAU, 2013, p. 107).

O tom produzido pelo texto, seja oral ou escrito, é, pois, o fator que lhe dá autoridade e permite ao leitor construir uma representação do corpo do enunciador (e não, evidentemente, do corpo do autor efetivo), fazendo emergir uma instância subjetiva que desempenha o papel de fiador do que é dito. Segundo Maingueneau, esta noção de ethos compreende não só a dimensão vocal, mas as dimensões físicas e psíquicas ligadas pelas representações coletivas à personagem do enunciador. São "[...] as propriedades que os oradores se conferiam implicitamente, através de sua maneira de dizer não o que diziam a propósito deles mesmos, mas o que revelavam pelo próprio modo de se expressarem" (MAINGUENEAU, 1997, p. 45).

Para Maingueneau, este modo de dizer, apresentar-se, expor-se, não se dá de modo individual, mas é resultado de inspirações psicológicas, segundo determinado posicionamento ideológico. A qualidade do ethos projeta-se à imagem de um "fiador", que através de seu discurso "confere a si próprio uma identidade compatível com o mundo que ele deverá construir em seu enunciado" (MAINGUENEAU, 2013, p. 108). Logo, a este fiador, cuja imagem o interlocutor deve construir por intermédio de diversos fatores, lhe é atribuído um caráter e uma corporalidade, cujo grau de precisão varia segundo o seu texto, o seu discurso. O “caráter”, segundo o autor, corresponde a uma gama de traços psicológicos; já a "corporalidade" designa a compleição corporal, a maneira de vestir-se e movimentar-se no espaço social. O ethos se constitui de uma disciplina do corpo por intermédio de um comportamento global. Fatores como "caráter" e "corporalidade" do fiador advêm de um conjunto difuso de representações sociais valorizadas ou desvalorizadas, sobre as quais se ancora a enunciação que, por sua vez, pode confirmá-las ou modificá-las. Contudo, cabe aqui lembrar que tais estereótipos culturais circundam nos domínios publicitários, artístico, cultural, educacional etc.

No seu texto Ethos, cenografia, incorporação, Maingueneau (2005, p. 72-73) elucida melhor a figura deste "fiador" ao dizer que este é a imagem de cada um de nós fazemos nos textos (orais ou escritos) ou nos silêncios que produzimos; é a imagem que cada um de nós queremos, projetamos, construímos ou, ainda, que gostaríamos de ter nos mais diversificados contextos. No entanto, uma vez que os indivíduos sejam constituídos de múltiplas identidades, o ethos também será múltiplo. Como exemplo, podemos citar um professor que assume um ethos autoritário ao ministrar uma aula presencial para uma turma de alunos universitários; na sua fala, enquanto professor que ministra determinada aula, esse ethos difere do ethos professor, por exemplo, de uma aula gravada

Fórum linguistic., Florianópolis, v.14, n.1, p.1849-1865, jan./mar.2017. 
(videoaula), que pode ser um ethos mais sedutor, simpático, apresentador. Esses ethé do professor tomarão forma nos discursos, em relação a seus diversos destinatários, nas variadas situações, esteja ele consciente deles ou não. Contudo, cabe ressaltar que o ethos não se deriva de uma escolha, mas se dá partir da imposição de determinada formação discursiva.

Como o ethos corresponde a um comportamento, este articula o verbal e o não verbal, provocando efeitos multissensoriais nos interlocutores. Pode ser compreendido como algo relativamente saliente, singular, coletivo, partilhado, implícito e visível, de modo que sua apreensão se concretiza na relação discursiva estabelecida entre o enunciador e seus interlocutores. O ethos ainda é concebido como algo relativamente fixo, convencional e ousado.

Segundo Maingueneau (2008, p. 17, grifo nosso):

- o ethos é uma noção discursiva, ele se constrói através do discurso, não é uma “imagem” do locutor exterior a sua fala;

- o ethos é fundamentalmente um processo interativo de influência sobre o outro;

- é uma noção fundamentalmente híbrida (sócio-discursiva), um comportamento socialmente avaliado, que não pode ser apreendido fora de uma situação de comunicação precisa, integrada ela mesma numa determinada conjuntura sócio-histórica.

O autor adverte que sua definição de ethos se inscreve em um quadro da Análise do Discurso que ultrapassa a proposta da retórica antiga, sem, contudo, romper totalmente com a concepção aristotélica. Trata-se de algo que vai além do processo de argumentação e persuasão, instituindo-se como o ato geral de anuência dos sujeitos a um certo discurso.

O auxílio de Maingueneau (2008), diferentemente de outras teorias que estudam a questão do ethos, é que este pode ser inferido de textos de distinta natureza enunciativa. Não é depreendido apenas de uma pessoa em situação de enunciação, de um discurso, no sentido lato do termo, mas pode ser observado em enunciados orais, escritos, na modalidade verbal, visual, ou verbo-visual, figurando uma pessoa ou até mesmo uma instituição.

Na teoria de Maingueneau (2008), a questão do gênero, por exemplo, é refletida no interior de uma cena genérica, logo o ethos se faz presente dentro de tal cena por meio de um viés mais discursivo. Já Bakhtin (1997) discorre sobre determinado tom que paira sobre os enunciados, materializados através dos gêneros, de modo a congregar até os próprios valores sociais. Quando Maingueneau discorre sobre ethos, Bakhtin alude à questão do estilo. Estilo é, pois, uma construção muito mais ampla que ethos, uma vez que o ethos nada mais é que parte do estilo.

Entendemos, assim, ser possível articular a teoria bakhtiniana à noção de ethos proposta por Maingueneau (1995) que, embora admita que o ethos seja origem de um sujeito enunciativo, discursivo e, portanto, divergente do sujeito ativo, real de Bakhtin, assevera que o ethos está ligado ao exercício da palavra e vinculado à enunciação que implica uma relação entre corpo e discurso. Segundo Maingueneau, o ethos tem uma ligação importante com a enunciação, pois, para ele,

É insuficiente ver a instância subjetiva que se manifesta por meio do discurso apenas como estatuto ou papel. Ela se manifesta também como voz e, além disso, como corpo enunciante, historicamente especificado e inscrito em uma situação, que sua enunciação ao mesmo tempo pressupõe e valida progressivamente (MAINGUENEAU, 1995, p. 70).

No momento em que Maingueneau refere-se à voz e ao corpo, compreendemos que não se trata do autor efetivo, mas do enunciador, ou seja, daquele que está inscrito na instância do discurso; o que há é um posicionamento discursivo do qual podemos extrair o universo de sentido que o discurso consente. As ideias postas em um discurso nos remetem a um modo de dizer e, consequentemente, a um modo de ser; a intenção do enunciador de um texto (ou de uma videoaula) é atrair um destinatário aos sentidos que estão sendo veiculados. Contudo, isso não quer dizer que o enunciador seja o centro do discurso; é necessário, a priori, que haja um lugar e momento próprios para a enunciação que, para o autor, seria a cena de enunciação. 
Consoante Maingueneau, o enunciador não se configura como um ponto de origem estável que se expressaria dessa ou daquela maneira, mas é levado em conta em um quadro profundamente interativo, em uma instituição discursiva inscrita em certa configuração cultural e que envolve papéis, lugares e momentos de enunciação legítimos, bem como um suporte material e um determinado modo de circulação do enunciado (MAINGUENEAU apud AMOSSY, 2005). Logo, o ethos é mostrado no discurso através das escolhas feitas ${ }^{1}$ através das possibilidades de dizer, o que nos faz refletir sobre o modo de produção e sobre o discurso veiculado nas videoaulas de escrita/redação científica.

\title{
3.1 UM DIÁLOGO COM BAKHTIN: APROXIMAÇÕES ENTRE ETHOS E ESTILO
}

Procurando aprofundar um pouco mais essa questão sobre as proximidades entre ethos e estilo, de modo que consigamos refletir sobre eles nas videoaulas que nos propomos analisar, discutiremos tal assunto sob o olhar de Discini (2015, p. 12, grifo do autor).

\begin{abstract}
Junto ao eco de que "o estilo é o homem", há outro, "o estilo são dois homens". No intervalo entre essas duas asseverações, movimentam-se nossas reflexões, que partem do princípio de que tudo tem estilo. Para isso, interrogamos como se apresenta no interior dos textos o homem-no-mundo - esse efeito de identidade que diz respeito ao sujeito concebido como a imagem de quem "fala" a partir dos próprios enunciados. É a imagem fincada no papel de um enunciador necessariamente pressuposto aos seus enunciados e semanticamente encarnado neles. Esses propósitos - que supõem pensarmos no estilo como desdobramento discursivo do ethos tal qual previsto pela retórica aristotélica - amparam-se numa operacionalização analítica que busca contemplar um modo recorrente e organizado de dizer, do qual resulta um modo próprio de ser no mundo.
\end{abstract}

Segundo a autora, esse modo próprio de dizer se dá através de mecanismos de construção de sentido que, imbricados nos enunciados, concebem corpo, voz e caráter ao que é dito ou escrito, promovendo o estilo como uma homogeneidade discursiva constitutivamente heterogênea através de uma estilística que fluidifica limites entre o eu e o outro, uma vez que assegura o aparecimento de um estilo por meio da ética e de estéticas próprias.

Distante de ser apenas como "um algo a mais" sobreposto a uma fala ordinária, ou seja, compreendido como um desvio em relação a determinada norma das manifestações estéticas, é possível pensar no estilo entre o estilo do gênero e o estilo autoral, sendo o homem visto como aquele que andarilha por diferentes esferas de comunicação. Assim, "[...] o estilo é concebido como o que emerge de coerções: dos gêneros [...]; de esferas da comunicação [...]; da própria homogeneidade do corpo (DISCINI, 2015, p. 12)”.

O enunciador, enquanto pessoa discursiva, se apropria de um corpo, de uma voz, de um caráter, apresentando-se como um ethos: "[...] imagem de quem diz, dada por um modo recorrente e organizado de dizer, na apropriação feita pela estilística discursiva, da noção de ethos [...]" (DISCINI, 2015, p.12). O estilo é visto como um fato diferencial, haja vista que o homem é compreendido como aquele se constrói na relação com seu outro, promovendo a alteridade. Logo, é da diferença entre ambos que o estilo emerge heterogeneamente, tendo no dialogismo seu principal suporte.

O analista, dessa forma, ao comparar estilos de determinados jornais, revistas, poemas, pinturas, videoaulas reconhecerá o estilo como um corpo contingente e uma estrutura aberta e a partir de uma totalidade de enunciados correlacionados entre si firma o estilo como uma presença no mundo.

Cada texto apresenta vetores de estilo, que reúnem as marcas da enunciação enunciada, as quais se estendem aos mecanismos de textualização. Tais marcas, espalhadas num único texto, remetem à totalidade, tal como o dado remete ao não dado. Assim os vetores fazem ver o todo que subjaz à parte(DISCINI, 2015, p. 14).

\footnotetext{
${ }^{1}$ Para a Análise do Discurso, a escolha pode ser feita dentro das possibilidades do interdiscurso. Logo, há possibilidades, mas não todas. Como não há aspectos intencionais, as escolhas são efetuadas dentro de uma determinada formação discursiva (é a formação discursiva que determina o que pode e deve ser dito pelo falante a partir do lugar, da posição social, histórica e ideológica que ele ocupa).
} 
A herança teórica oferecida pela obra de Bakhtin, segundo Discini (2010), favorece o pensamento do estilo, associado a um ethos, como a representação de um sujeito inacabado, cujo estatuto dialógico promove uma ética e uma estética. Assim, ao procurar obter da palavra do homem, constitutivamente uno e duplo, o modo peculiar de ser responsivo, concebe o estilo como fato diferencial.

Ao englobar não somente a questão da expressividade posta na valoração do locutor diante do seu objeto de discurso, mas também compreender as tonalidades dialógicas, bem como a relação do locutor com seu interlocutor, Bakhtin retrata a questão do estilo, já que "[...] o índice substancial (constitutivo) do enunciado é o fato de dirigir-se a alguém, de estar voltado para o destinatário [...]" (BAKHTIN, 1997, p. 320, grifo do autor). No entanto, este destinatário pode ser de distintas instâncias, desde o interlocutor direto do diálogo até um outro não concretizado determinado pelas distintas áreas da atividade humana. A quem o enunciado é dirigido, a forma como o locutor imagina e percebe o seu destinatário, o modo como o destinatário pode influenciar o enunciado, tudo isso influi na composição e no estilo do enunciado.

O locutor, deste modo, leva em conta como sua fala será recebida pelo destinatário, o grau informacional deste diante da situação, bem como as suas opiniões, convicções, preconceitos, seus conhecimentos, já que tudo isso interferirá na compreensão responsiva do enunciado a ser proferido. Uma vez refletidas tais características, dar-se-á a escolha do gênero do discurso, como também dos recursos linguísticos a serem empregados, compondo o estilo do seu enunciado. Segundo Bakhtin (1997, p. 324) "[...] o estilo depende do modo que o locutor percebe e compreende seu destinatário, e do modo que ele presume uma compreensão responsiva ativa $[\ldots] "$.

O autor considera que o "estilo" é algo acoplado aos gêneros do discurso, destaca que por meio dele é que a individualidade do falante/escritor pode ser refletida, todavia, diz que nem sempre é possível ao sujeito representar sua individualidade estilística, pois alguns gêneros exigem uma forma padronizada de linguagem, como, por exemplo, documentos oficiais, artigos científicos etc. Atenta, também, para o fato de que o estilo caracteriza-se como o "epifenômeno" do enunciado, já que não se escreve com determinado estilo, é o estilo que acaba sendo o produto - consequência do escrito/fala (e/ou do vídeo).

Nas palavras de Amorim (2004, p. 111):

O estudo dos estilos só pode ser feito em relação direta com o estudo dos gêneros. Quando se faz passar um estilo de um gênero a outro, não somente se modifica a ressonância desse estilo de um gênero a outro, não somente se modifica a ressonância desse estilo como também se renova o gênero em questão [...]. É ao nível do gênero que se registram e se estabilizam as novas formas de estruturação dos enunciados. 'Lá onde há estilo, há gênero’.

Dentro do quadro teórico bakhtiniano, vamos entender ethos na relação entre tom e estilo. O tom alude a determinado horizonte social, fomentando tons valorativos. Já o estilo é parte característica do gênero. O estilo situa-se no como dizer tipicamente a partir de um determinado gênero. Assim, um ethos que incorpora os valores sociais tem a ver com o tom e o estilo em Bakhtin. Logo, o conceito de ethos faz-se importante em nossas análises, pois, nas videoaulas analisadas, há a imagem de um determinado sujeito ("professor-apresentador") que necessita ser observada para a produção de sentidos neste tipo de gênero digital. Dentro das possibilidades de dizer de determinado gênero, de determinado grupo social, há marcas que caracterizam suas formas de dizer; por isso, pensaremos a questão do ethos no sentido de aproximá-lo à questão do estilo de Bakhtin ${ }^{2}$, bem como de construir uma imagem desse sujeito ("professor-apresentador”) na relação com o seu destinatário.

\footnotetext{
${ }^{2}$ Cabe aqui ressaltar que as possibilidades oferecidas pelo lugar entre fronteiras teóricas, isto é, estudos acerca do discurso e a filosofia bakhtiniana da linguagem, permitem refletir não só sobre o ethos ou sobre o estilo, mas também sobre a natureza da linguagem.
} 


\section{O "EU-PROFESSOR", O "EU-PROFESSOR-APRESENTADOR": CONFIGURAÇÕES DO ESTILO DE UM ETHOS DISCURSIVO}

Em qualquer discurso, ao enunciar em uma dada situação comunicativa, o locutor mobiliza mecanismos favoráveis à construção de uma imagem de si, que é moldada ou reelaborada por seus interlocutores. Essa imagem que o locutor revela de si mesmo no discurso é denominada de ethos. No momento em que este locutor profere o seu discurso, tal sujeito constrói diversas imagens que dialogam com seu destinatário, como meio de incentivá-lo e convencê-lo para a veracidade de suas informações. E são essas imagens erigidas através de marcas do sujeito que, ao emergirem em seu discurso, nos permitem verificar a constituição do ethos deste sujeito.

Posto isso, vemos, através dos postulados de Maingueneau, como se dá o ethos discursivo dos "professores-apresentadores" das videoaulas de escrita e redação científica, de modo a perceber como este se associa com a questão do estilo em Bakhtin, uma vez consideramos aqui que o ethos nada mais é que parte estilística de determinada enunciação.

Advindo do termo grego, ethos significa personagem, funcionando como uma imagem que o enunciador/locutor constrói de si no discurso para impressionar o seu destinatário, ganhando, como consequência, a sua confiança. Fiorin (2004, p. 134) destaca que o ethos está diretamente ligado à adesão deste destinatário no momento do discurso. Assim, este último não adere ao discurso apenas porque ele é exibido como um conjunto de ideias que exprimem seus possíveis interesses, ele adere ao discurso porque se identifica com o dado sujeito da enunciação, com seu caráter, com seu corpo, com seu tom, com suas vozes sociais, com seu estilo. Com Bakhtin, podemos dizer que o discurso não é apenas um conteúdo, mas também um modo de dizer que se configura através do projeto de dizer daquele locutor, de maneira a constituir os sujeitos de determinada enunciação. O discurso, ao construir e ser construído por um enunciador, constrói também seu(s) destinatário(s).

A respeito da teoria aristotélica, Fiorin (2007) menciona que é o ethos do orador que vai propiciar a credibilidade da informação, pois quando o discurso é organizado, o orador inspira confiança. Todavia, todas essas qualificações que o destinatário faz do seu locutor, no momento em que ele desempenha uma perfomance, dependem do ponto de vista de quem observa, que segundo Fiorin (1989) não são julgamentos individuais, mas sociais. Logo, dependem dos valores que os homens exercem, dialogicamente, nas relações com os outros. Segundo Maingueneau, (2008), o ethos é uma noção discursiva, que se constrói através do discurso, não é uma "imagem" do locutor exterior à sua fala; é também um processo interativo de influência sobre o outro; é uma noção fundamentalmente híbrida (sociodiscursiva), um comportamento socialmente avaliado, que não pode ser assimilado fora de uma situação de comunicação precisa, integrada numa determinada conjuntura sócio-histórica.

Tendo em vista tais considerações, para a análise que nos interessa aqui realizar, a partir de um olhar dialógico sobre as videoaulas youtubianas de escrita/redação científica, percebemos como a figura do "professor-apresentador" se legitima, uma vez que esta está associada a duas grandes instituições de ensino: USP e UNESP.

Para esta interpretação, buscamos verificar como se manifestam os discursos de apresentação ${ }^{3}$ dos "professores-apresentadores" veiculados como forma de configurar o ethos de tais enunciadores. Observemo-los.

\footnotetext{
${ }^{3}$ Lembramos que as partes negritadas de tais discursos destacam o que pretendemos inicialmente analisar, no entanto o restante do texto também se faz necessário para que possamos ter uma compreensão abrangente de outros fatores que contribuem para a formação do ethos discursivo dos locutores das videoaulas. Nesse sentido, cabe também salientar que algumas palavras estão propositalmente sublinhadas com o objetivo de demarcarem alguns recursos prosódicos e conversacionais que omitimos em outros excertos, mas que, neste momento, se fazem presentes em razão do nosso propósito de análise.
} 
EC1: "Olá a todos... sejam muito bem-vindos... meu nome é Valtencir Zucolotto e eu sou coordenador do grupo de nanomedicina e nanotoxicologia do Instituto de Física da USP de São Carlos... estou aqui com vocês hoje pra apresentar nosso curso de escrita científica... produção de artigos de alto impacto... um curso que foi criado né... com base na nossa experiência nos últimos 6 ou 8 anos... ministrando disciplinas relacionadas à escrita científica... e o curso está agora totalmente on-line em forma de videoaulas... o nosso curso é dividido em duas grandes partes... a primeira parte do curso é voltada ao gênero literário da escrita científica e à estrutura de um artigo científico... onde nós fazemos um raio x do ponto de vista linguístico em cada uma das seções de um artigo científico regular... e a segunda parte do curso é voltada para estilo e linguagem da escrita científica... e no final... nós temos as notas sobre o processo editorial ...[...]”. (grifo nosso) [Apresentação]

RC1: “[... Ééé... eu queria primeiramente agradecer a possibilidade de tá aqui conversando com vocês né... que me foi oferecida pela Universidade Estadual Paulista... a UNESP... eee... em particular à pró-reitoria de pós-graduação... a professora... a professora Marilza... nossa pró-reitora de pós-graduação... e também ao grupo do NEAD... queee trabalhou e fez todo esse processo comigo né... na construção desses vídeos [...]”. (grifo nosso) [Aula 1]

RC2: “[...] O que eu vou colocar pra vocês nesse curso de redação cientifica... ééé... na verdade parte da minha experiência... parte da minha história e parte de todos os estudos que eu tenho feito na área evidentemente... tenho aprendido com muitas pessoas... principalmente com editores científicos... com revisores científicos em revistas de bom padrão né... tenho estudado a área... tem várias pessoas estudando isso... publicando artigos... e tem a minha experiência pessoal que também pesa um pouco nisso né... eu também atuo como editor científico... também já levei várias pedradas por isso como editor cientifico né... uma situação difícil aqui no Brasil principalmente na hora em que você é colocado no panorama internacional... mas estamos na luta e parte disso... vai tá transcrita... vai tá transposta pra esse curso... e a minha experiência... ela traz uma... uma vertente interessante que depois vocês vão entender um pouco melhor quando eu falar da minha abordagem... ééé... quando eu comecei a fazer ciência né... eu de fato tinha aquela ilusão do grande cientista... de fazer ciência geral e paralelamente a isso eu fui me infiltrando... ééé... nas questões da filosofia da ciência... muito mais porque eu via que meu orientador valorizava isso né... e eu acabava... ééé... buscando... uma vez que eu o admirava... eu acabava buscando entender um pouco mais dessa área... daaa... filosofia da ciência... e fiz isso arduamente... sempre publiquei ou tentava publicar em revistas de boa qualidade internacional... isso há trinta anos atrás... 25 anos atrás... fazendo essa jornada né... e era assim uma coisa por idealismo... eu acreditava que a ciência era internacional... quando chega mais no final da década de noventa vem um processo de globalização que começa a colocar o Brasil no cenário internacional ... aí as pessoas começam de fato a perceber a necessidade da... ééé... internacionalização da pesquisa... era algo que eu já vinha fazendo como outros cientistas brasileiros também faziam né... mas a gente fazia de uma forma meio... ééé... propensa... por achar que a ciência era isso... lógico que tinha uma base filosófica por trás que nos dizia que o caminho era esse... mas na prática você via pessoas publicando em revistas de baixo escalão... passando na sua frente e você ficava meio sem entender... mas eu sempre me neguei... às vezes escapa um ou outro mas isso era contra a minha vontade... mas eu sempre me neguei a publicar em revistas de baixa qualidade ou de tão baixa qualidade né... então essa história né... foi me mostrando particularmente da... da... virada do século pra cá o quanto eu tava no caminho certo e o quanto a questão era essa... ao longo dessa vivência eu como professor e como alguém que gosta de ensinar... sempre gostei de ensinar... né... em qualquer área que fosse... desde que eu soubesse alguma coisa honestamente... ééé... nessa experiência eu fui... ééé... criando cursos... enfim dando aula de redação científica... a primeira delas... oficial pelo menos... começou em 86... 1986... quer dizer... já faz vários anos né... então nessa trajetória... eu fui cada vez mais... ééé... me conduzindo pra esse caminho... e isso que era $20 \%$ da minha atividade... hoje constitui praticamente $80 \%$ da minha atividade... mas eu não posso largar a minha especialidade... que eu trabalho na verdade com fisiologia e comportamento de peixes né... mas eu consegui construir um discurso que é geral dentro da ciência né... e se aplica às três grandes áreas... então a minha experiência foi levando a esse caminho... esse é um pedaço curto porém significativo da minha história dentro da redação científica né... o meu primeiro livro eu publiquei em 98... e de lá pra cá as coisas foram aumentando e eu acredito que tenho conseguido trazer um aspecto positivo pra redação científica em nosso país... motivo que me faz então... ééé... disponibilizar um vídeo né... com um curso sobre redação científica [...]". (grifo nosso) [Aula 1] 
É produtivo e pertinente que observemos, nos trechos destacados ${ }^{4}$, como em tais discursos os enunciadores produzem um elogio de si e são construídos de forma a dar credibilidade ao dizer pela valoração positiva do sujeito que diz. Vemos, já de início, nos dois cursos analisados, o mencionar das universidades a que pertencem os professores das videoaulas, USP e UNESP, como forma de instituir legitimidade e autoridade aos dizeres proferidos nas aulas, uma vez que são renomadas instituições de ensino conhecidas nacional e internacionalmente e, como consequência, prestigiadas pela população em geral, pois são tidas como representações sociais valorizadas. É, portanto, devido a este contexto sócio-histórico, construído e partilhado socialmente, que o ethos de tais professores é também constituído.

No entanto, dando continuidade à observação de seus discursos, é possível que notemos a visibilidade dada às suas áreas de atuação, bem como ao tempo de trabalho e estudo dedicado à escrita/redação científica. A inserção do tempo, reproduzida aqui através dos trechos EC1: “[...] com base na nossa experiência nos últimos 6 ou 8 anos...", RC2: "[...] sempre publiquei ou tentava publicar em revistas de boa qualidade internacional... isso há trinta anos atrás... 25 anos atrás..." ou em RC2: "[...] eu fui... éé... criando cursos... enfim dando aula de redação científica... a primeira delas... oficial pelo menos... começou em $86 \ldots$.. 1986... quer dizer já faz vários anos né..", denota uma maior capacidade de se falar sobre tal assunto por salientar a experiência laboral dos professores nesta área específica. Tal situação dialoga com a máxima instaurada na sociedade, nos negócios ou na própria ciência de que a experiência é fator primordial para a aceitabilidade de determinado trabalho, contratação, validação de teorias científicas, etc.

Somado a isso, vê-se também este caráter de credibilidade, na última parte do discurso do professor Volpato, reproduzido, através do excerto RC2 "[...] o meu primeiro livro eu publiquei em 98... e de lá pra cá as coisas foram aumentando... e eu acredito que tenho conseguido trazer um aspecto positivo pra redação científica em nosso país..."; a informação por ele dita sobre a publicação de seu primeiro livro em 1998 e sua capacidade e aptidão em falar sobre este assunto. Marcas como essas, além de possuírem um viés comercial, devido ao marketing estabelecido pela venda dos seus livros, possibilitam também o engrandecimento e o enaltecimento da figura do professor.

Eé pensando nesta figura do professor que não podemos nos esquecer de salientar o ethos na construção de um discurso pedagógico, quando, na própria apresentação dos cursos, o professor lança mão de escolhas lexicais na constituição dos seus discursos, as quais visam didatizar o enunciado proferido, haja vista a própria complexidade do tema (escrita/redação científica).

Se o estudo da escrita/redação científica fosse mediado apenas por livros e manuais, certamente, tais materiais sofreriam as coerções da formalidade por se tratar de um assunto complexo e categórico, bem como por estar atrelado a este tipo de suporte. Tendo em vista que o divulgar sobre escrever/redigir cientificamente está, em nosso corpus, anunciado sob a forma de videoaulas youtubianas, podemos notar tais "ensinamentos" sendo divulgados a partir da concepção de aula. Vemos, assim, variadas formas de dizer sobre a escrita/redação científica em razão deste outro gênero. Frases retiradas dos excertos acima como em EC1: "[...] nós fazemos um raio $\mathrm{X}$ do ponto de vista linguístico de cada uma das seções de um artigo científico regular...", RC2: "[...] também já levei várias pedradas com isso como editor cientifico né...", RC2: “[...] mas estamos na luta e parte disso... vai tá transcrita, vai tá transposta pra esse curso..." ou mesmo em outros trechos como em RC3: "[...] Quantos cientistas já leram vários livros do Paulo Freire? Poucos... não é... então nós temos que entrar de sola nisso..." (Aula 1) mostram estratégias dos professores que, em meio a um assunto formal, mesclam expressões coloquiais como forma de aproximar o aluno deste discurso complexo.

Embora se trate de um gênero que cumpre um roteiro a ser seguido, sendo, portanto, extraído de uma suposta pauta escrita, por exemplo, a oralidade é constituinte de tal gênero, fato esse que pode ser visto no prolongamento da vogal "e" nas sequências "ééé" e "queee" em RC2 e RC1 respectivamente, bem como através da expressão "ahn" ou nas repetições "da... da...", as quais funcionam como unidades articuladoras do discurso oral. Já vocábulos como "né", postos em EC1, RC1 e RC2, funcionam como marcadores de busca de apoio pelos "professores-apresentadores" durante o momento de suas enunciações. Tais encadeamentos monossilábicos fazem-se constantes neste tipo de gênero, o qual apesar de ser falado também segue a prévia de um possível roteiro (com edições, cortes, arranjos, etc.) como forma de organização do discurso e das aulas.

\footnotetext{
${ }^{4}$ Para assegurar nossa imparcialidade com relação aos dados inseridos neste trabalho, ressaltamos que os textos destacados, bem como os excertos transcritos das videoaulas apresentam extensões diferenciadas devido ao fato de o curso de Escrita Científica se resumir em 8 videoaulas, enquanto o de Redação Científica ser composto por 42 aulas; logo os dizeres de cada professor também variam mediante esta construção composicional.
} 
Nesta contiguidade de modalidades, torna-se possível também notar uma afluência entre o "eu-professor-apresentador" e seu(s) destinatário(s), quando, por exemplo, no curso de Redação Científica, o professor Gilson Volpato conta parte de sua trajetória acadêmica, (RC2: “... tenho aprendido com muitas pessoas... principalmente com editores científicos... com revisores científicos em revistas de bom padrão né...”), descreve o início de suas pesquisas (RC2: “... quando eu comecei a fazer ciência né... eu de fato tinha aquela ilusão do grande cientista... de fazer ciência geral e paralelamente a isso eu fui me infiltrando... ééé... nas questões da filosofia da ciência...”), relembra as orientações de seu antigo orientador (RC2: “... eu via que meu orientador valorizava isso né... e eu acabava... ééé... buscando... uma vez que eu o admirava... eu acabava buscando entender um pouco mais dessa área...”), enfatiza o seu gosto por ensinar (RC2: “... sempre gostei de ensinar... né... em qualquer área que fosse... desde que eu soubesse alguma coisa honestamente") etc.

Práticas como essas configuram o ethos do professor que entende as dificuldades pelas quais passam seus "alunos" (ou mesmo as dificuldades encontradas pelos próprios professores, uma vez que as videoaulas são dirigidas, primordialmente, a este público, tendo em vista seus dizeres na introdução do curso), que encoraja, que estimula, que ama o que faz, proporcionando uma aprendizagem mais agradável e prazerosa.

Somado a isso, vemos também, no discurso deste professor, o uso de analogias, que, através de uma ação processual de mudança linguística, altera a forma de um modelo já existente de enunciado para enquadrá-lo de maneira mais acessível ao entendimento. Trechos como o que veremos a seguir denotam, mais uma vez, a necessidade de o professor se aproximar de seu(s) outro(s) de maneira mais pedagógica e educacional, de modo a comparar as fraudes nas publicações científicas com exemplos do cotidiano.

RC4: “[...] É... é... evidente... é falado constantemente né... é... o famoso publish or perish... ou seja... você publica né... ou você tá danado... não é verdade? Ou você publica ou você morre cientificamente... então essa é uma pressão que existe... em todo mundo... a mesma pressão que existe pra um jogador de futebol... o jogador de futebol... ou ele joga bem... é escalado... ou ele não vai dar em nada... não é? Um corredor de fórmula 1 ou ele tá entre os primeiros ou ele não existe... então são coisas que existem em qualquer profissão... um empresário... ou ele cresce ou ele definha... então isso é em qualquer lugar na verdade... um professor também... ou ele ensina ou ele não ensina... então são coisas que existem em qualquer área [...] é importante que você entenda que essa pressão... ela faz parte do jogo... tá? Agora essa pressão não é motivo pra você querer aumentar numericamente seus trabalhos de forma fraudulenta... não é? Veja... se as pessoas falam assim... a pressão por publicação tá levando os indivíduos a inventarem dados... a serem autores fraudulentos... a cometerem equívocos éticos dentro da ciência... não... não é a pressão por publicação que faz isso... me desculpe... mas não é... porque se eu admitir que a pressão por publicação faz isso... eu tenho que admitir que um indivíduo por falta de dinheiro vai virar bandido... será que isso é verdade? Será que quem rouba só são os mais pobres? Será? Provavelmente não... então veja... a questão que tá por trás é uma questão ética e moral do indivíduo... a pressão pode ser justificativa dos fracos de conceito... não? Então veja... o indivíduo pode tá sem dinheiro para comprar comida... mas ele vai dá um jeito de conseguir resolver a comida de uma forma honesta... é pedir pra alguém... não vai roubar... não é? [...]”. (grifo nosso) [Aula 25]

Enfatiza-se a atividade docente que, socialmente, além de ser aquela que detém o saber, também é marcada pelo auxílio, pelo educar, pelo ser facilitador e didatizante que desperta no aluno a vontade de aprender, através de formas de dizer claras e descomplicadas. O uso de analogias, como estratégia facilitadora dos conteúdos apresentados, relaciona-se a situações do dia a dia, como a alusão feita ao futebol, à fórmula 1, à postura adotada pelo empresário ou até mesmo ao próprio ato ilícito de roubar praticado pelo bandido, fazendo com que os seus destinatários ("alunos-usuários") tenham exemplos simples e de fácil entendimento para questões, muitas vezes, complexas, como é o caso do plágio científico. 
Cabe aqui ressaltar que as analogias integram o processo cognitivo humano e ainda auxiliam na compreensão dos conceitos científicos por aproximarem domínios heterogêneos. Desse modo, um domínio menos familiar (conceito científico a ser esclarecido), sendo, no nosso caso, "o plágio científico", é tornado compreensível por semelhança com domínios mais familiares, de modo a auxiliar o processo de ensino do docente, bem como constituir o seu saber-fazer professoral.

Todavia, este saber-fazer é diretamente influenciado pela sensibilidade do "professor-apresentador" que, ao projetar a estranheza de seus alunos com relação a determinado conteúdo, faz uso deste tipo de recurso para que seus presumidos destinatários compreendam melhor suas colocações, oportunizando uma aproximação mais intensa do seu outro. Faz então das aulas uma instância que fortalece e afiança o ethos que o identifica através de tais práticas pedagógicas. Nesse panorama de interlocução, o "euprofessor", que já possui o ethos imposto pela profissão, busca construir o seu estilo pessoal e idealizar determinadas caracterizações para seus destinatários, que assumem o papel de "coenunciadores", podendo, assim, avaliar esse ethos por ele assumido. Nesse cenário, Bakhtin/Voloshinov (2006) alerta justamente para a necessidade de se discernir, na apreensão do discurso, até que ponto as suas expressões e particularidades são distintamente percebidas e possuem significação social, pois se o discurso for percebido como impenetrável pelo narrador (locutor), este deve escolher um caminho mais seguro para proferi-lo.

É, pois, nesse intermeio que o "eu-professor-apresentador" também entra em cena, afinal tem-se uma corporeidade associada a uma compleição corporal, a uma forma de vestir-se e de mover-se no espaço proporcionado pelas videoaulas, a um tom, a uma dimensão vocal do enunciador, desvelada pelo seu próprio discurso. Logo, tais elementos estão apoiados sobre um conjunto de representações sociais, bem como de estereótipos sobre os quais a enunciação se apoia quando se pensa na constituição do fazer-se apresentador. Tal é a verdade desta situação que Maingueneau (2008) já se referia ao ethos não somente como uma dimensão vocal, mas também ao conjunto das determinações físicas e psíquicas atribuídas pelas representações coletivas à personagem do orador (locutor).

Nessa construção de imagem, podemos entender um pouco os motivos da tentativa dos professores em se tornarem apresentadores, no momento, por exemplo, em que fazem uso da bancada, no modo de olhar para a câmera, na forma de gesticular, no posicionamento vocal. Em razão do suporte a que tais videoaulas estão vinculadas e devido à construção composicional deste tipo de enunciado, professores assumem, em seu projeto de dizer, comportamentos advindos de outras esferas de comunicação como forma de abarcar um maior número de "alunos-usuários", dispostos (ou “impostos”) a aprender ou adquirir seus serviços e/ou produtos.

No entanto, neste ponto, é possível notarmos algumas diferenças na constituição de cada curso de escrita e redação científica, haja vista sua maneira de dialogar com as formas representativas desse meio midiático baseado em um "fazer telejornalístico".

Nas videoaulas de Escrita Científica, tem-se o diálogo com as formas de se fazer um jornalismo dito objetivo, que teoriza a neutralidade não apenas da informação, mas, sobretudo, da linguagem não verbal, em que gestos e expressões são rigorosamente controlados do ponto de vista técnico e editorial. Entendemos, assim, que as videoaulas deste curso, ao trazerem, durante todas as aulas ministradas, a bancada onde está posto o "professor-apresentador", a sua forma social de trajar-se, os cortes de imagem entre os conteúdos apresentados em tela e a sua imagem exibida na aula (muitas vezes até sobrepostas, de maneira a observar as duas cenas simultaneamente), buscam proporcionar credibilidade à informação veiculada de modo a dialogar com as formas figurativizadas da ambientação de um telejornal, como do seu próprio apresentador. Logo, a seriedade é a voz que ecoa neste ambiente enunciativo, sendo este o tom principal conferido a tais videoaulas que dialogam diretamente com o conceito de objetividade jornalística, bem como com a própria objetividade científica.

Fórum linguistic., Florianópolis, v.14, n.1, p.1849-1865, jan./mar.2017. 


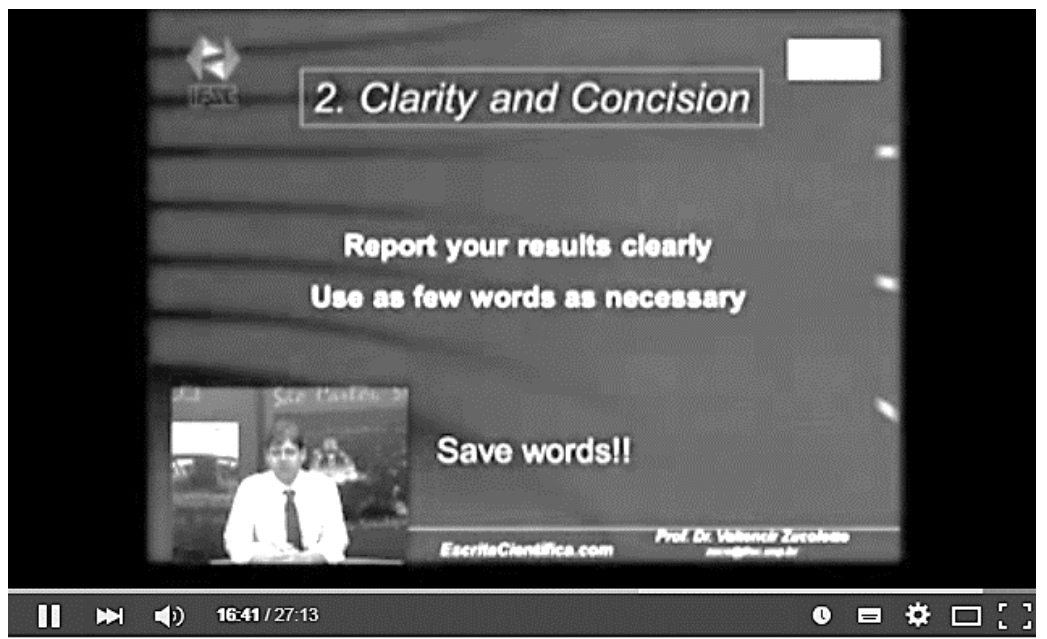

Módulo 01 - " $O$ Gênero Literário" - Curso de Escrita Científica

Figura 1: Disposição dos elementos nas videoaulas de Escrita Científica

Fonte: Zucolotto (2014)

Na figura acima, é possível percebermos a imagem do "professor-apresentador" reduzida ao canto esquerdo inferior da tela, por meio de recursos técnicos da própria produção da videoaula, juntamente com o conteúdo exposto no restante da tela. Essa disposição de informações não é aleatória, pois, além de dialogar com o padrão jornalístico já mencionado, instaura determinada dialogicidade à cena mediante o contato visual posto tanto no conteúdo quanto no "professor-apresentador", de modo a dar credibilidade a este tipo de enunciado, que, diferentemente de outros tipos de videoaulas, (como, por exemplo, aquelas produzidas de maneira mais amadora e inseridas em sites como o YouTube) promove a divulgação de informações de forma mais completa e não por intermédio apenas de sons, sem imagem de quem as apresenta ou mesmo fazendo auxílio somente da tela do computador. Vemos, assim, que o processo de transmissão do conhecimento ocorre, nestas aulas, por meio de movimentos complexos, através dos quais as videoaulas disponibilizam recursos audiovisuais que possibilitam um contato visual com o seu locutor ("professorapresentador") e com as informações disponibilizadas em tela. A partir de seus enquadramentos (muito utilizados na esfera jornalística), tais aulas buscam promover mais possibilidades para que seus destinatários ("alunos-usuários") se "apropriem” dos conteúdos acessados.

Ao analisarmos as videoaulas de Redação Científica, podemos também perceber tal caráter jornalístico principalmente na aula introdutória, a qual tem por objetivo apresentar resumidamente ao destinatário o tema (ou os temas) que será desenvolvido e de que forma este será exposto ao longo do curso. No entanto, neste curso, diferentemente do anterior, vê-se a intenção do "professorapresentador" em situar-se em contextos mais espontâneos como uma forma também de promover a interação com o seu destinatário. Este tipo de representação dialoga com as novas formas apregoadas pelo jornalismo moderno que trazem uma nova configuração enunciativa ao permitir que o apresentador se movimente com maior intensidade, proporcionando a produção de um efeito de informalidade, descontração, proximidade (HERNANDES, 2012). Dialoga também com as experiências de profissionais que trabalham com a produção de videoaulas, ao mencionarem que "[...] quanto maior o [seu] grau de interatividade, maior a [sua] capacidade de retenção do assunto" (CLOUD-EAD, 2014). Por esse motivo, o vídeo necessita ser dinâmico e não reproduzir as mesmas posturas de um professor em uma sala de aula presencial.

Nas videoaulas de Volpato, vê-se, então, a figura do professor que, diferentemente do curso de Escrita Científica, ministra suas aulas em pé, movimentando-se diante de sua lousa eletrônica para a explicação dos conteúdos expostos, mas, ao mesmo tempo, não deixa de olhar para câmera, mantendo sempre ativa a interação com seu destinatário presumido. O seu "eu-professor" funde-se neste processo enunciativo de maneira a transformá-lo em um personagem criado a partir de sua própria representação: "eu-professorapresentador".

Vejamos a disposição dos elementos nas videoaulas de Redação Científica posta nas imagens abaixo: 


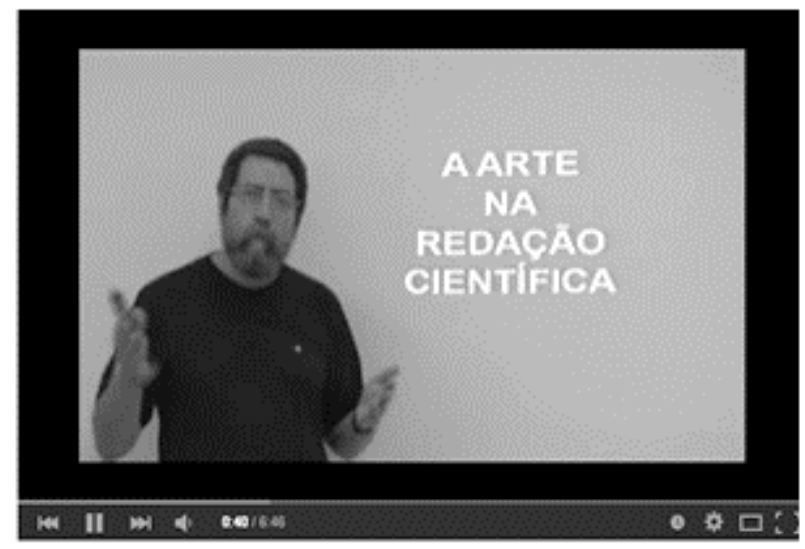

AULA. 22 - A ARTE NA REDACAO CIENTIFICA.wmV

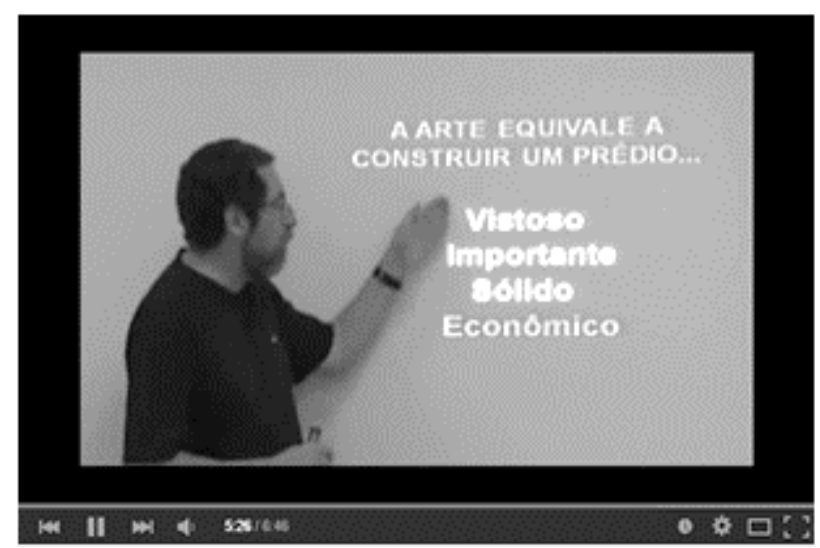

AULA 22 - A ARTE NA REDACAO CIENTIFICA.wmV

Figura 2: Disposição dos elementos nas videoaulas de Redação Científica

Fonte: Volpato (2014)

Vemos, neste tipo de docência, pautada no Ensino Informal a Distância (EIaD) ${ }^{5}$, em que o professor lida com diferentes ethé constitutivos de sua imagem, procedentes de distintas vozes, ou seja, aquela que busca ensinar, aquela que busca apresentar-se, aquela que busca vender.

Ainda que nas videoaulas não se tenha um destinatário disposto fisicamente no tempo-espaço da enunciação, o qual interage sincronicamente com os dizeres dos "professores-apresentadores", este destinatário torna-se um destinatário presumido, logo, também é agente atravessador dos dizeres dos enunciadores das videoaulas.

Nesse atravessamento, o "eu-professor-apresentador" das videoaulas constitui-se através de diferentes formas: o professor que ensina (eu-professor), o que apresenta ("eu-professor-apresentador"), o que comercializa seus serviços e produtos ("eu-professorapresentador-comerciante"), caracterizado através do desdobrar de vários "eus”, com marcas identitárias daquele que "ministra/apresenta/vende". Nesse sentido, pode também constituir-se segundo as funções atreladas ao próprio conteúdo da aula que ministra sobre escrita/redação científica, assumindo também um ethos marcado, por exemplo, pelo "eu-professorapresentador-cientista”.

Todavia, uma vez que este "eu-professor-apresentador" é atravessado pelos dizeres alheios, marcado pela constituição alteritária de ser, torna-se, assim, um "eu-outro-professor", um "eu-outro-professor-apresentador", um "eu-outro-professor-apresentadorcomerciante", um "eu-outro-professor-apresentador-comerciante-cientista". Ao assumir diversas funções, o seu eu é parte constituinte do atravessamento alheio, ou seja, do outro indivíduo, de outro(s) discurso(s), enfim, do dialogismo que o fundamenta.

${ }^{5}$ Expressão denominada por nós para referir-se ao Ensino Informal a Distância (EIaD) através de videoaulas inseridas em sites de arquivamento de vídeos como o YouTube, cujo objetivo é a disseminação de informações de maneira informal, sem vínculos estritamente formais com a academia. 
Para isso, a constituição desse ethos deve ser muito bem planejada, pois uma aula sobre escrita/redação científica ministrada presencialmente, de certo modo, impõe ao aluno a obrigação de assisti-la ainda que este não tenha gostado do conteúdo, do professor, etc. Contudo, uma videoaula youtubiana ${ }^{6}$ sobre tal temática necessita, a todo momento, ser representativa, chamar a atenção de seu(s) possível(eis) destinatário(s), uma vez que este tipo de "leitura multimodal", propiciado pelos recursos tecnológicos da contemporaneidade, promove a transitividade de vídeos de modo instantâneo e, consequentemente, uma maior navegabilidade entre os vídeos selecionados pela plataforma do YouTube, fazendo com que muitos dos usuários possam dispersar-se ou traçar formas outras de leitura.

Assim, ao recorrermos ao conceito de ethos, proposto por Maingueneau, podemos associá-lo ao conceito de estilo, segundo o entende o Círculo de Bakhtin, já que todo enunciado, ao se fazer ecoar, pressupõe um sujeito enunciador (locutor), o qual, ao produzir um enunciado, utiliza-se de um determinado estilo que se relaciona ao estilo do gênero do discurso mobilizado. E foi em busca deste ethos/estilo, que recortamos videoaulas sobre escrita/redação científica e, a partir desse recorte, examinamos as recorrências de modos de dizer que remetem a um modo de ser professor (apresentador) no mundo da internet.

Se ethos está associado a estilo, uma vez que o ethos nada mais é que parte estilística de determinada enunciação, o conceito de estilo, segundo a perspectiva dialógica da linguagem, proposta por Bakhtin e pelos membros de seu Círculo, deixa de ser tratado na sua individualidade e passa a implicar interação. Como pode ser visto em o Discurso na vida e discurso na arte (BAKHTIN/VOLOSHIVOV, [1926], p. 16):

O estilo do poeta é engendrado do estilo de sua fala interior, a qual não se submete a controle, e sua fala interior é ela mesma o produto de sua vida social inteira. 'O estilo é o homem', dizem; mas poderíamos dizer: o estilo é pelo menos duas pessoas ou, mais precisamente, uma pessoa mais seu grupo social na forma do seu representante autorizado, o ouvinte - o participante constante na fala interior e exterior de uma pessoa.

Assim como já vimos, o ethos de tais professores se forma segundo o estilo próprio de enunciarem, o qual, todavia, não se produz individualmente, mas é engendrado pelas relações socioideológicas de interação entre sujeitos. Baseia-se, desse modo, nas formas constitutivas do ser professor, as quais são produzidas pelas caracterizações auferidas pelo ser aluno, que, seguindo também as atribuições conferidas pela própria sociedade, denota a ele (o professor) a responsabilidade de ensinar e de ser um exemplo a se seguir. Logo, confere-lhe modelos de atuação, tendo em vista o seu modo de falar, vestir-se, situar-se neste cronotopo propiciado pelas videoaulas youtubianas.

Para ancorarmos este nosso posicionamento, atentamo-nos a outra obra do Círculo, Marxismo e Filosofia da Linguagem (2006), na qual Bakhtin/Voloshinov, ao exibir um estudo sobre o estilo das formas de citação da palavra alheia (discurso direto, discurso indireto, discurso indireto livre), ressalta a importância dos discursos de outrem para a constituição dos discursos próprios. De acordo com o autor, o estilo tem uma ordem própria, ou seja, organiza, segundo o seu modo, os discursos do outro e os elementos da língua, sem negar o caráter individual do autor; em contrapartida, sempre é visto como um fenômeno social, já que ele sempre se relaciona com os enunciados alheios.

Já na obra Estética da Criação Verbal (BAKHTIN, 1997), o estilo é incorporado como um dos elementos que caracteriza o gênero (conteúdo temático, construção composicional e estilo). Assim, tais elementos, ao estarem intrinsecamente ligados no todo do enunciado, são também determinados pela especificidade de uma determinada esfera, e uma vez que a compreensão da língua se dá a partir de gêneros do discurso, os textos criados pela sociedade funcionam como mediadores entre o locutor e o destinatário (entre "professor-apresentador" e "aluno-usuário").

\footnotetext{
${ }^{6}$ Estudar o gênero videoaula youtubiana como uma atualização do gênero aula, bem como da própria videoaula, é uma maneira de compreender como o gênero se atualiza em razão das esferas e do suporte nos quais ele se engendra. Segundo nosso posicionamento, uma videoaula em VHS ou DVD é diferente de uma videoaula de Ensino a Distância (EaD), que é diferente de uma videoaula inserida no YouTube. Apesar de todas serem constituintes do gênero videoaula, suas especificidades proporcionam possibilidades outras de interpretação e produção discursiva. Ao se produzir uma videoaula, cujo principal objetivo é inseri-la em uma plataforma de compartilhamento de vídeos como o YouTube, faz-se necessário a utilização de estratégias específicas voltadas a esse tipo de suporte.
} 
Com isso posto, percebemos que o estilo, por sua vez, passa a ser compreendido em sua relação com o gênero no qual se concretiza, de modo que cada esfera da atividade e da comunicação humana tenha o seu estilo próprio. Assim como em cada esfera há o emprego de diversos gêneros, tais gêneros passam a assumir determinadas características estilísticas, temáticas e composicionais. Refletindo sobre os enunciadores das videoaulas de escrita/redação científica inseridas no YouTube, vemos como estes assumem um estilo que incorpora o ethos do professor que ensina, que apresenta, que comercializa ("professor-apresentador-comerciante"), haja vista que tais aulas são interceptadas não apenas por uma esfera didático-pedagógica, mas também por uma esfera midiáticocomercial. Nesse sentido, o seu locutor engendra as características (o estilo) que necessita assumir em razão de tais esferas.

Dessa forma, para a criação de um ethos, é necessário que o locutor assuma determinado estilo, conferido por todo um entorno situacional. Só assim um ethos captará certo conjunto de representações sociais e reproduzirá determinado tom de voz e caráter, de modo a termos uma estilização do estilo. Quando um ethos é identificado nas enunciações, sua presença restabelece no discurso as relações de poder, fazendo-se presente ainda que não seja textualmente ou visualmente marcado. Logo, no gênero videoaula youtubiana de escrita/redação científica, sua voz sustenta o discurso e, simultaneamente, é sustentada por ele. O projeto de dizer de seus enunciadores se constitui tendo em vista como o outro vai constituí-lo, bem como a sua esfera de atuação e os elementos situacionais e ideológicos que integram este tempo-espaço enunciativo.

\section{CONSIDERAÇÕES FINAIS}

Por meio deste estudo, procuramos mostrar como a imagem do professor se ressignifica, tendo em vista suas formas de apresentação a partir de novos recursos tecnológicos, advindos do surgimento de diferentes mídiuns (suporte). Assim, ao analisarmos as videoaulas de escrita/redação científica, percebemos os diversos ethé assumidos pelos "professores-apresentadores" de tais aulas, a partir da inclusão deste gênero no ciberespaço.

Neste contexto, vemos que o professor se coloca como apresentador, fazendo-se valer de inúmeros recursos, como montagens de cenário, aperfeiçoamento da postura vocálica, utilização de expressões discursivas típicas do discurso pedagógico, técnicas de marketing, constituição de um ethos discursivo atraente, discursos de credibilidade, possibilitando o ecoar de distintas vozes que se entremeiam neste discurso, favorecendo a construção da figura de um ethos altruísta.

No processo de interação com o outro, vemos como o "professor-apresentador" de tais videoaulas, ao se posicionar através desse ethos altruísta, passa a utilizar-se de analogias como forma de facilitar o entendimento de seus destinatários ("aluno-destinatário"). Incorpora um ethos didático e facilitador, passando a utilizar exemplos concretos, advindos do campo da engenharia, por exemplo, o qual tem como base a aplicação de conhecimentos científicos e métodos empíricos, calcados em materialidades exatas e racionais.

Toda a dimensão corporal (vestuário, tom, voz, etc.) inserida nas videoaulas analisadas denota um conjunto de representações sociais sobre as quais a enunciação se apoia para a valorização do fazer-se apresentador. Como mostra de um discurso professoral, há também um ethos que o identifica através de determinadas práticas pedagógicas, como, por exemplo, ao lançar mão de expressões coloquiais, analogias, exemplos pessoais, as quais têm como meta aproximar, estimular e encorajar os seus destinatários à compreensão de assuntos tidos como complexos, como é o caso da própria escrita/redação científica. É assim que o seu "euprofessor" funde-se neste processo enunciativo de maneira a transformá-lo em um personagem criado a partir de sua própria representação: "eu-professor-apresentador".

Como meio de atingir a atenção e compreensão dos seus destinatários ("alunos-usuários"), o locutor (professor) passa a se constituir através de diferentes ethé, configurando-se, assim, como "professor-apresentador" das videoaulas, as quais também assumem acabamentos específicos no momento em que a aula, ao transformar-se em videoaula youtubiana, se põe a dialogar com o caráter telejornalístico e cinematográfico de sua produção. 


\section{REFERÊNCIAS}

AMORIM, M. O pesquisador e seu outro. São Paulo: Musa, 2004.

AMOSSY, R. (Org.). Imagens de si no discurso: a construção do ethos. São Paulo: Contexto, 2005.

\section{BAKHTIN, M.; VOLOSHINOV, V. N. Discurso na vida e discurso na arte.}

Trad. Carlos Alberto Faraco e Cristovão Tezza, [1926]. Circulação restrita. Disponível em < http://www.uesb.br/ppgcel/DiscursoNa-Vida-Discurso-Na-Arte.pdf > Acesso em: jan. 2014.

Marxismo e filosofia da linguagem: problemas fundamentais do método sociológico da linguagem. 12. ed. São Paulo: Hucitec, 2006.

BAKHTIN, M. Estética da criação verbal. São Paulo: Martins Fontes, 1997.

CLOUD-EAD. Videoaulas objetivas e com exemplos práticos são preferência de alunos. Disponível em: <http://cloudead.programmers.com.br/blog/videoaulas-objetivas-e-com-exemplos-praticos-sao-preferencia-de-alunos/> Acesso em: 26 de jun. 2016.

DISCINI, N. Ethos e estilo. In: MOTTA, A. R.; SALGADO, L. S. (Org.) Ethos Discursivo. São Paulo: Contexto, 2008. p. 33-54.

Bakhtin: Contribuições para uma estilística discursiva. In: PAULA, L. de; STAFUZZA, G. (Org.). Círculo de Bakhtin: teoria inclassificável. Volume1. Série Bakhtin - Inclassificável. Campinas: Mercado de Letras, 2010. p. 115-148.

Inquietações sobre o estilo. Todas as letras z, São Paulo, v. 17, n. 2, p. 12-17, maio/ago. 2015.

FIORIN, J. L. A lógica da neutralidade: um caso de aspectualização do ator. In: SEMINÁRIOS DO GEL, 18., 1989, São Paulo. . Anais... São Paulo: Dedalus/Acervo USP-FFLCH-LE, 1989. p. 348- 355.

O ethos do enunciador. In: CORTINA, A.; MARCHEZAN, R. C. (Org.). Razões e sensibilidades: a semiótica em foco. Araraquara: Laboratório Editorial FLC/UNESP/Cultura Acadêmica Editora, 2004. p. 117-138.

O sujeito na semiótica narrativa e discursiva. Todas as letras J, São Paulo, v. 9, n.1, 2007. Disponível em: $<$ http://editorarevistas.mackenzie.br/index.php/tl/article/view/649/579http://editorarevistas.mackenzie.br/index.php/tl/article/vi ew/649/579>. Acesso em: 10 fev. 2015.

HERNANDES, N. A mídia e seus truques: o que jornal, revista, tv, rádio e internet fazem para captar e manter a atenção do público, São Paulo: Contexto, 2012. 
MAINGUENEAU, D. O contexto da obra literária. Trad. Marina Appenzeller. São Paulo: Martins Fontes, 1995.

Novas tendências em análise do discurso. Campinas, São Paulo: Pontes / Ed. da Unicamp, 1997.

Ethos, cenografia, incorporação. In: AMOSSY, R. (Org.). Imagens de si no discurso: a construção do ethos. São Paulo: Contexto, 2005, p. 69-92.

A propósito do ethos. In: MOTTA, A.R.; SALGADO, L. (Org.). Ethos discursivo. São Paulo: Contexto, 2008. p. 11-29.

Análise de textos de comunicação. São Paulo: Cortez, 2013.

VOLPATO. G. A arte na redação científica. Vídeo (6min46s). Disponível em: <http://www.youtube.com/watch?v=sztd3m2bgw0\&list=PL838A236D33BA042E\&index=21 >. Acesso em: 16 out. de 2014.

ZUCOlOTTO. V. O gênero literário: Curso de Escrita Científica. Vídeo (27min13s). Disponível em: <http://www.youtube.com/watch?v=CZR0ptpPaR0\&index=2\&list=PL3yYSVIdSmKk-79Gn240Pr3NUNe8Os0S0>. Acesso em: 14 out. 2014. 